Boise State University

ScholarWorks

$1-1-2017$

\title{
Acoustic and Aerodynamic Data on Somali Chizigula Stops
}

Michal Temkin Martinez

Boise State University

Vanessa Rosenbaum 


\title{
Acoustic and Aerodynamic Data on Somali Chizigula Stops \\ Michal Temkin Martinez and Vanessa Rosenbaum
}

\begin{abstract}
18.1. Introduction
In recent years, traditional language descriptions as well as preservation and revitalization efforts have benefited from experimental approaches utilized in other fields of linguistics." The integration of phonetic experimental methods has assisted in scientifically defining certain articulatory and acoustic parameters that would be impossible to identify otherwise (Hudu et al. 2009; Miller 2008; Miller \& Finch 2011). Additionally, the use of psycholinguistic methods in O'Grady et al. (2009) aids in the documentation and assessment of language fluency for language revitalization purposes. This chapter reports acoustic and aerodynamic data collected to complement the description of stops in Somali Chizigula. Results from this study will also contribute to the ongoing discussion of the typology of $\mathrm{N}+$ stop sequences.
\end{abstract}

\subsubsection{LANGUAGE BACKGROUND}

Somali Chizigula (also Mushungulu; xma, G311) is natively spoken in the Lower Jubba Valley in Somalia. The language is also spoken by Somali-Bantu refugees in neighboring countries, and in the diaspora throughout the United States and the United Kingdom. A census conducted in 2006 found approximately 23,000 speakers in Somalia (Lewis et al. 2013). There is no standardized orthography for Somali Chizigula, and only one book has been written in the language. Moreover, although there are several preliminary analyses (Odden et al. 2011; Pillion 2013) and several documentation projects underway (Hout 2012; Tse 2013), relatively little is known about the language. 
Speakers of Somali Chizigula are descendants of slaves brought to Somalia from northern Tanzania in the 19th century. Many Somali-Bantu were able to escape from slavery and settle in the Lower Jubba Valley. In the time the Somali-Bantu have spent in Somalia, language contact with Italian and Somali has led to the lexicalization of many borrowings ${ }^{1}$ During the decades following the onset of the Somali civil war (c. 1978), many Somali-Bantu have sought refuge in neighboring countries. A large number of Somali Chizigula speakers also speak Somali, Swahili, and Maay.

Kizigua (ziw, G31), the language of our speakers' ancestors, is still spoken in present-day Tanzania. Our comparison of lexical items in Somali Chizigula with those in two Kizigua dictionaries (Kisbey 1906; Mochiwa 2008) suggests that the two varieties' lexicons have diverged beyond the point of mutual intelligibility as a result of sound changes and language contact with non-Bantu languages. In recent years limited work has been published on Kizigua, with its main focus on stress and tone (Kenstowicz 1989; Kenstowicz \& Kisseberth 1990; Kisseberth 1992). ${ }^{2}$

\subsubsection{PROJECT BACKGROUND}

The present study is part of a larger documentation project begun in 2011 at the request of the Somali Chizigula-speaking community in Boise, Idaho, United States. Our research team, including Jon P. Dayley, Mwaliko Mberwa, and Michal Temkin Martinez, is currently in the final stages of compiling a bilingual ChizigulaEnglish/English-Chizigula dictionary (Dayley et al. 2017). As work has progressed on the dictionary, several phonetically and phonologically interesting properties have emerged, specifically among the stops and accompanying nasals. In addition to having a relatively large inventory of contrastive stops, Somali Chizigula (unlike Kizigua) contains implosives. The voiceless and voiced prenasalized stops differ not only in the voicing status of the oral portion of the stops, but also in the voicing of their nasal portion. It is difficult to hear the prenasalization in the voiceless series, so it is important to document other phonetic attributes that would presumably aid the listener in perceiving the contrast. For this reason, we collected aerodynamic data to provide a more thorough description of the acoustic properties of the stops in the language. In this chapter, we first describe the stop inventory, followed by exploratory acoustic and aerodynamic data collected. Our discussion of the results of this study includes implications for the typology of $\mathrm{N}+$ stop sequences and related language change.

\subsubsection{THE ROLE OF EXPERIMENTAL DATA COLLECTION IN THE INTERPLAY BETWEEN THEORY AND LANGUAGE DOCUMENTATION}

In recent years, the field of documentary linguistics has moved away from relying on the researcher's role as observer and describer toward a more empirical approach to gather, record, and provide language data to speech community members as well 
as linguists (Thieberger 2009). While language documentation projects focused on endangered languages serve predominantly to aid speech communities with preservation and revitalization efforts, they also help to inform typological generalizations and linguistic theory (Woodbury 2011),

In language documentation, the use of experimental methods and phonetic instrumentation not only enhances the ability to describe sound systems of understudied languages, but also serves to crucially link phonetic analysis and phonological theory, providing additional means to evaluate phonological theories (Hudu et al. 2009). Production studies using articulography and ultrasound have aided in providing data for theories concerning tongue root phenomena (Hudu et al. 2009; Maddieson 1993), and others have used articulatory and acoustic data to record more accurate descriptions of the sounds studied (Lee-Kim et al. 2014; Miller et al. 2009). In addition to these production studies, theories of perception have also benefited from the use of data collected during fieldwork that was later manipulated (DiCanio 2012).

In the current study, the use of aerodynamic data is especially pertinent in the description of Somali Chizigula prenasalized voiceless stops. In some of our initial comparisons with Kizigua, we believed that the prenasalized voiceless stop from the Tanzanian variety had undergone effacement $\left(n t \rightarrow n t^{\mathrm{h}} \rightarrow \mathrm{t}^{\mathrm{h}}\right)$ in Somali Chizigula, as in Swahili (Hyman 2003), with complete effacement occurring in word-initial position and only partial devoicing post-vocalically. In a conversation with our main consultant, he confirmed the presence of a "silent" nasal in word-initial position and illustrated this with exaggeration by flaring his nostrils when producing the segment.

\subsubsection{ACOUSTIC METHODOLOGY}

Initial audio recordings were made using a Shure SM10A head-mounted unidirectional dynamic microphone and a Zoom $\mathrm{H} 4 \mathrm{n}$ recorder in a sound-attenuated room. The resulting data, presented in section 18.2, confirmed the lack of activity in the acoustic signal that led to our decision to collect aerodynamic data, which we report in section 18.3. The sole participant was the main consultant on the documentation project. During data collection in 2013, he was 29 years old, had lived in the United States for seven years, and had received some high school education as a refugee in Kenya. He also speaks English, Swahili, Somali, and some Maay.

Tokens for these recordings (available in Appendix A) include five plosive/implosive (near-) minimal pairs, 20 words containing the prenasalized voiceless stops, 15 words containing the prenasalized voiced stops, and 14 words containing the syllabic nasal. Voice onset timing (VOT) was measured using the procedure outlined in Lisker \& Abramson (1964), by identifying the first glottal pulse and measuring the length of time between this point and the release of the stop and the start of the following vowel by identifying "an abrupt onset of energy in the formant frequency range." 


\subsection{Acoustics of stops and $\mathbf{N}+$ stop sequences}

The stop inventory of Somali Chizigula is relatively large. In addition to a complete set of voicing contrasts, it contrasts plosives and implosives, as well as prenasalized and plain plosives, as seen in (1).

(1) Contrastive stop inventory.

\begin{tabular}{|l|l|l|l|l|}
\hline & Bilabial & Alveolar & Palatal & Dorsal \\
\hline \multirow{2}{*}{ Plosive } & $\mathrm{p}$ & $\mathrm{t}$ & & $\mathrm{k}$ \\
\hline & $\mathrm{b}$ & $\mathrm{d}$ & $\mathrm{f}$ & $\mathrm{g}$ \\
\hline \multirow{2}{*}{ Prenasalized Plosive } & $\mathrm{mp}$ & $\mathrm{nt}$ & & $\mathrm{g} \mathrm{k}$ \\
\hline & $\mathrm{mb}$ & $\mathrm{nd}$ & & $\mathrm{gg}$ \\
\hline Implosive & $\mathrm{6}$ & $\mathrm{d}$ & & $\mathrm{g}$ \\
\hline Nasal & $\mathrm{m}$ & $\mathrm{n}$ & $\mathrm{n}$ & $\mathrm{g}$ \\
\hline
\end{tabular}

\subsubsection{VOICED PLOSIVE/IMPLOSIVE CONTRAST}

Voiced plosives and implosives in Somali Chizigula contrast in the bilabial, alveolar, and velar places of articulation. The plosives are slightly aspirated and are in lexicalized borrowings from Italian, Somali, and English. We speculate that the aspiration of these segments is present to maximize the contrast between loans and words native to Tanzanian Kizigua. The minimal pairs in (2) illustrate this contrast in the language.

(2) Plosive/implosive contrasts.

\begin{tabular}{|c|c|c|}
\hline $\begin{array}{l}\text { bosi } \\
\text { bhosi }\end{array}$ & $\begin{array}{l}\text { [6osi] } \\
{\left[b^{\mathrm{f}} \text { osi] }\right.}\end{array}$ & $\begin{array}{l}\text { 'boss' } \\
\text { 'cripple(d)' }\end{array}$ \\
\hline $\begin{array}{l}\text { udala } \\
\text { udhale }\end{array}$ & $\begin{array}{l}\text { [udala] } \\
\text { [ud }{ }^{\text {fiale] }}\end{array}$ & $\begin{array}{l}\text { 'stinginess' } \\
\text { 'greedy' }\end{array}$ \\
\hline 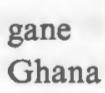 & $\begin{array}{l}\text { [gane] } \\
\text { [g }{ }^{\mathrm{G}} \text { ana] }\end{array}$ & $\begin{array}{l}\text { 'dormitory' } \\
\text { 'Ghana' }\end{array}$ \\
\hline
\end{tabular}

Acoustically, the plosive/implosive contrast is most evident in word-medial position, where the implosive exhibits sustained voicing throughout the closure, while in the plosive, voicing tapers off during the closure, leading to slight aspiration (17ms-25ms) at the release. This is seen in the waveforms shown in (3), with thin lines marking the segments' borders and shading highlighting the sustained voicing of the implosive in (a) and the aspiration of the plosive in (b). Close-up versions of the waveforms, highlighting only the stops and their surrounding vowels, are in Appendix B. 

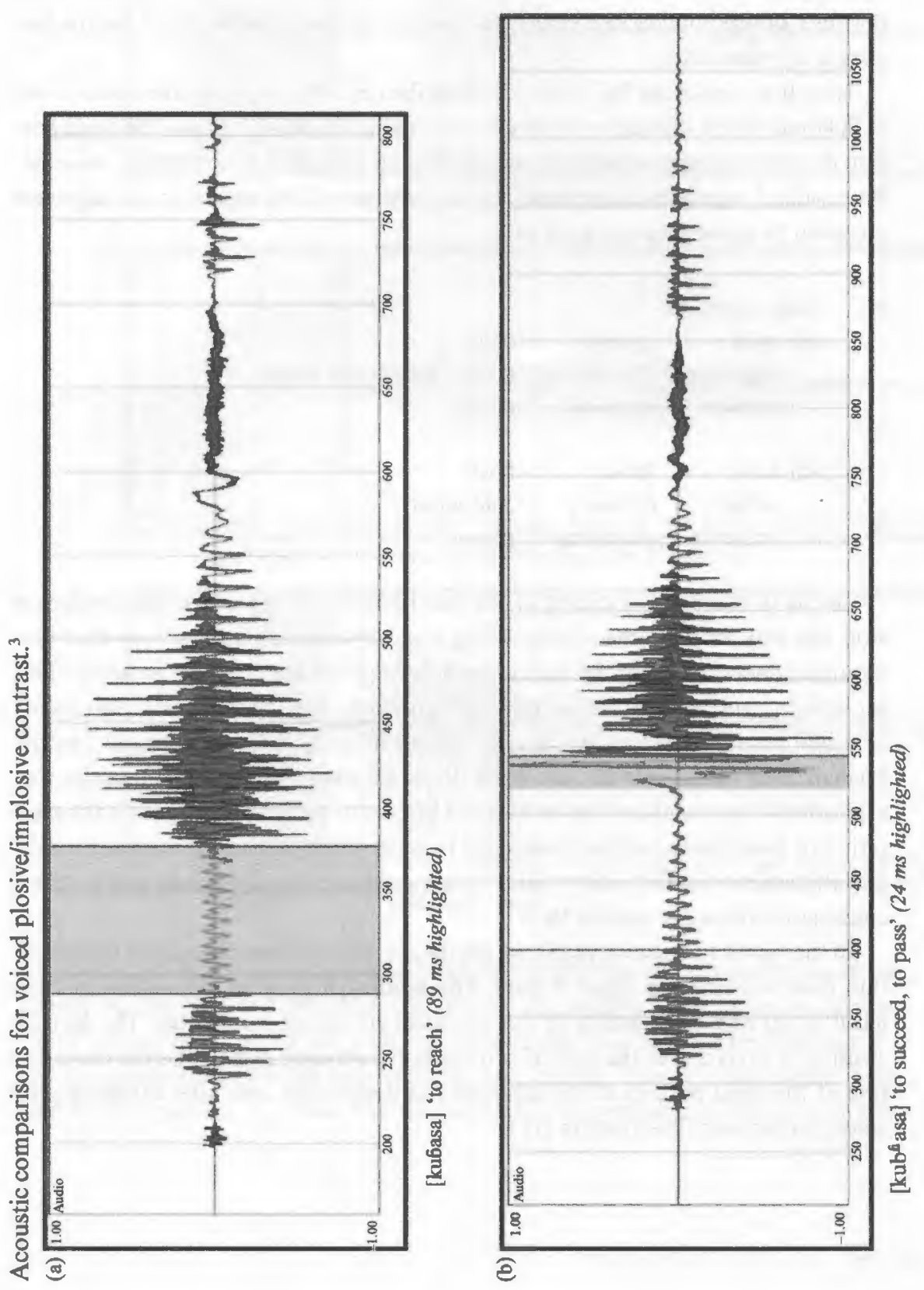

으 


\subsection{2. $\mathrm{N}+$ STOP SEQUENCES}

As in many Bantu languages, word-initial N+stop sequences in Somali Chizigula can be either prenasalized stops or syllabic nasals followed by oral stops. Prenasalized stops in Somali Chizigula are homorganic, and the nasal and stop portions of the sounds also match in voicing, as described for other Bantu languages (Hyman 2003).

Note that, unlike the NÇ sequences described by Huffman \& Hinnebusch (1998) in Pokomo, where voicing in the nasal is maintained partially or fully, the nasal portion of voiceless prenasalized plosives in Somali Chizigula is completely voiceless. Prenasalized segments contrast with both non-prenasalized segments and segments preceded by syllabic nasals, as in (4).

(4) Stop contrasts

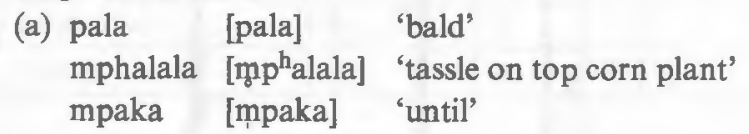

(b) bosi [6osi] 'boss'

mbeho [m6eho] 'cold wind'

mbantu [ṃbantu] 'person'

Owing to complete devoicing of the nasal portion of the prenasalized voiceless stop, the only acoustic cue distinguishing regular voiceless plosives from their prenasalized counterparts is the aspiration following the prenasalized plosives. ${ }^{4}$ This aspiration, considered a "reflex" of prenasalization (Maddieson 2003), also occurs in other Bantu languages to varying degrees (Cewa, Kongo, Pokomo, Swahili; Hyman 2003; Maddieson \& Ladefoged 1993). Khoisan languages demonstrate that aspiration of prenasalized segments is not limited to pulmonic stops, with the aspiration of prenasalized clicks (Miller 2011; Traill 1985). A discussion of aspiration and effacement due to the constraint on sequences containing nasals and voiceless consonants follows in section 18.5 .

In the waveforms shown in (5), we see the acoustic contrast illustrated in (4) with thin lines marking the labial closure. The shading highlights the audible syllabic nasal in (a) and nasalization in the prenasalized voiced stop in (c). The lack of shading in (b) is due to the lack of activity in the acoustic signal, and the demarcation of the nasal portion of the sequence was determined only after examining the aerodynamic data illustrated in (11). 
(5) Acoustic contrasts for syllabic $\mathrm{N}+$ stop/prenasalized segments.

(a)

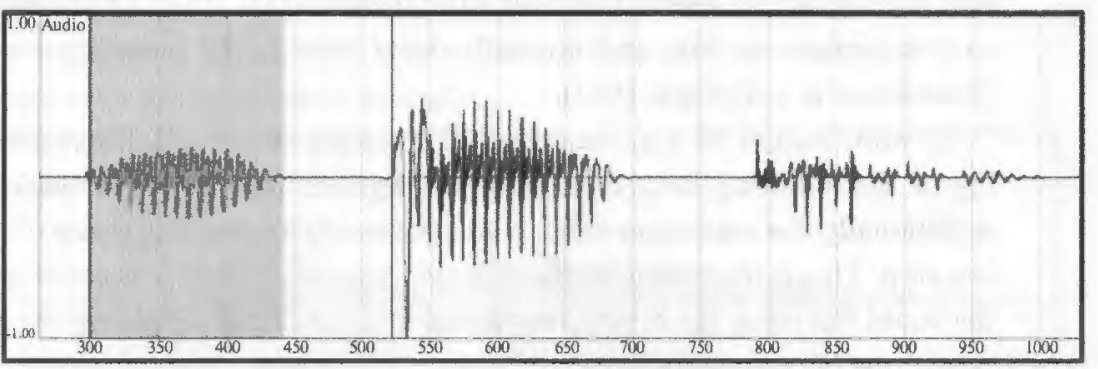

[mpaka]

'until' ( VOT = $26 \mathrm{~ms}$; $\mathrm{nasal}=150 \mathrm{~ms}$ )

(b)

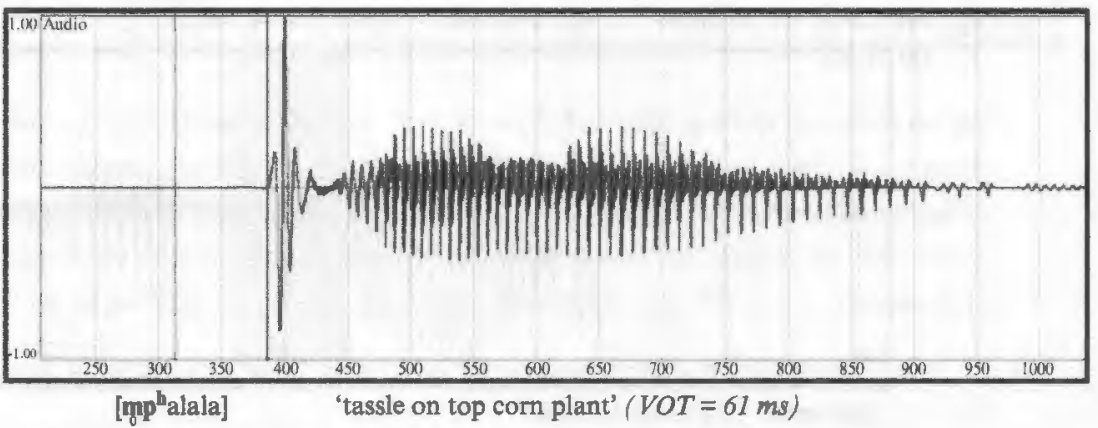

(c)

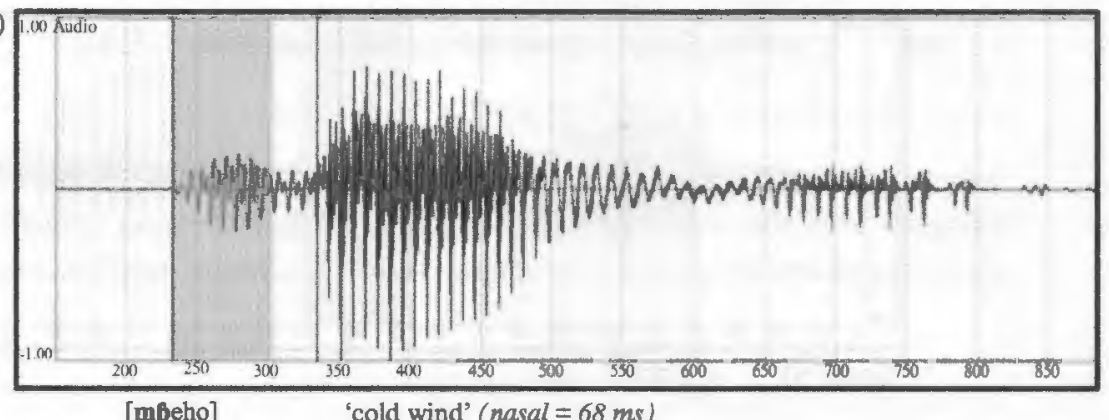

Note that the release of the voiceless plosive in both (a) and (b) results in a burst. However, the VOT for the plosive following the syllabic nasal in (a) is substantially shorter than that of the prenasalized voiceless stop in (b). The nasal portion of the prenasalized voiced stop in (c) is, as expected, substantially shorter than the syllabic nasal in (a). Note that Somali Chizigula prenasalized voiced stops are 
imploded, as is seen by the relatively high sustained amplitude in the voicing of the oral portion of the segment following the shaded nasal in (c). Cross-linguistically, such sequences are rare and normally occur only across morpheme boundaries (Maddieson \& Ladefoged 1993).

In word-medial $\mathbf{N}+$ stop sequences, the voicing of the nasal matches the voicing of the following stop, even when the segment preceding the nasal is voiced. Additionally, the aspiration reflex is still present following the release of the voiceless stop. This is illustrated in (6), with thin lines marking the onset of voicing for the vowel following the $\mathrm{N}+$ stop sequence, and shading highlighting the nasal portion of the $\mathrm{N}+$ stop sequence.

(6) Acoustic waveforms for word-medial N+stop sequences. ${ }^{5}$

(a)

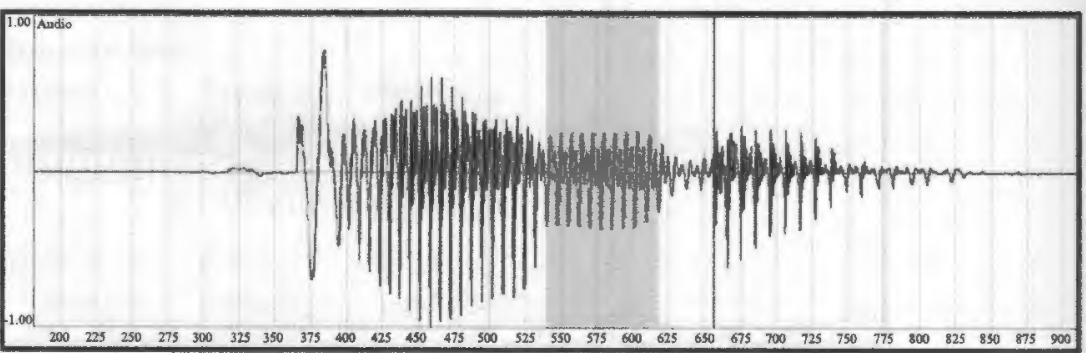

[mphemfia] 'com on the cobb'

(b)

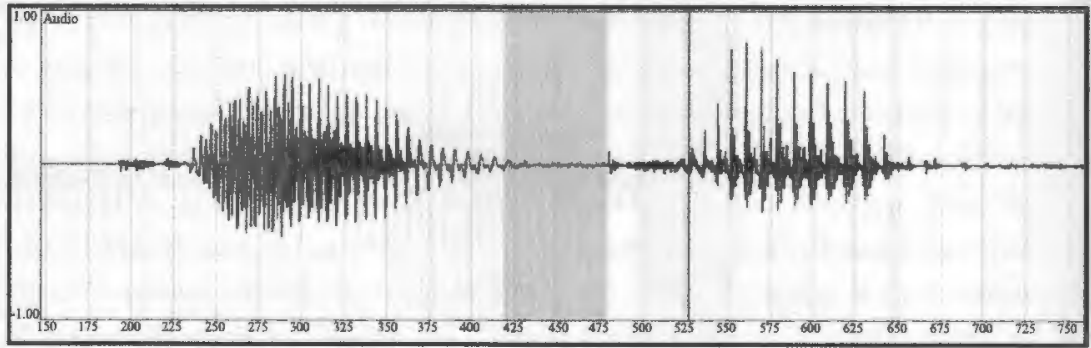

[kwiijk ka] 'to give to'

VOT measurements for the prenasalized stops reveal interesting patterns. Measurements ranged from $-38 \mathrm{~ms}$ to $-7 \mathrm{~ms}$ (average $-16 \mathrm{~ms}$ ) for the voiced prenasalized stops, and from $59 \mathrm{~ms}$ to $109 \mathrm{~ms}$ (average $74 \mathrm{~ms}$ ) for the voiceless prenasalized stops, with the voiceless stops having longer VOT, as expected. VOT is known to vary with place of articulation, with the longest VOT attributed to dorsal stops (Peterson \& Lehiste 1960). Such was the case with our data, with the labial [mp $\mathrm{p}^{\mathrm{h}}$ ] having the shortest VOT $(21 \mathrm{~ms}$ to $76 \mathrm{~ms}$, average $49 \mathrm{~ms})$, the velar [ $\left[\mathrm{g} \mathbf{k}^{\mathrm{h}}\right]$ having the longest VOT $(47 \mathrm{~ms}$ to $130 \mathrm{~ms}$, average $78 \mathrm{~ms})$, and the coronal [n $\mathrm{n}^{\mathrm{t}}$ ] nearly as long as the velar at $37 \mathrm{~ms}$ to $98 \mathrm{~ms}$ VOT (average $71 \mathrm{~ms}$ ). This relatively long VOT for the coronal stop results in a perceived voiceless tap $[s]$ or trill $[r]$ following the release 
of the stop. The long burst following the release of the stop is highlighted in the acoustic data in (7).

(7) Acoustic data for [n $\mathrm{t}^{\mathrm{h}}$ angulu] 'basket'.

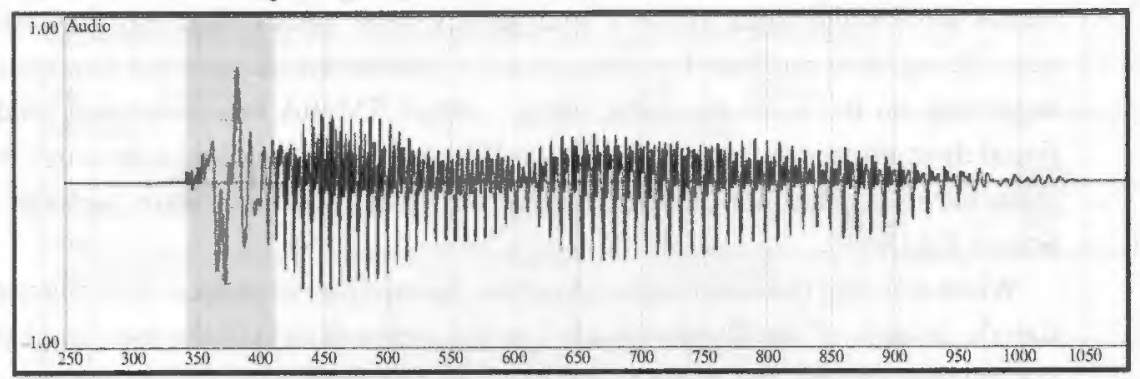

Given the acoustic data in section 18.2 , one cannot assert what the state of the nasal in prenasalized sequences is - that is, whether the nasal has undergone complete effacement or whether it is merely devoiced. As such, we conducted an exploratory aerodynamic investigation, measuring nasal and oral airflow to determine this, as well as to provide further evidence for the implosives. We present these data in the next section.

\subsection{An exploratory aerodynamic investigation}

\subsubsection{INTRODUCTION}

Aerodynamic measurements of oral and nasal airflow were collected to compensate for the difficulty in acoustically detecting devoiced nasals, as well as to illustrate the oral pressure fluctuations in the labial implosives and their contrasting plosives.

\subsubsection{METHODS}

A total of 67 tokens was recorded and analyzed. In addition to five minimal and near-minimal pairs for the plosive/implosive contrast, between five and eight words (depending on availability) containing a prenasalized stop were selected for each of the stops. Two stimuli containing syllabic nasals were also selected for each of the stops. The full list of stimuli can be found in Appendix A. The stimuli were presented orthographically in both Chizigula and English on a computer screen in order to eliminate possible confusion with synonyms in Chizigula. Although the participant is fluent in English and worked with researchers to develop the Chizigula orthography, the experimenter read the English gloss for each word to the participant, whose visual field was partially obstructed by the nasal and oral 
masks. Following the experimenter's prompt, the participant said the token in Chizigula three times.

Aerodynamic data were gathered using the Scicon R\&D system, containing a nasal mask, an oral mask, and a transducer. ${ }^{6}$ Although the aerodynamic equipment allows for simultaneous acoustic and aerodynamic data collection, the resulting acoustic signal is muffled. For this reason, acoustic recordings were also obtained separately on the same occasion, using a Shure SM10A head-mounted unidirectional dynamic microphone and a Zoom $\mathrm{H} 4 \mathrm{n}$ recorder in a sound-attenuated room. Data were collected and analyzed using the MacquirerX software package from Scicon R\&D.

When utilizing the nasal and oral masks, the equipment collects four channels of signals. In each of the illustrations below (examples (8)-(11)), the top signal shows the (muffled) audio, the second and third signals show oral airflow and pressure, and the bottom signal shows nasal airflow. All channels were recorded at a sample rate of $22,050 \mathrm{~Hz}$, with the aerodynamic channels set to a $150 \mathrm{~Hz}$ filter rate with a gain of 8 . The presence of the audio signal, though muffled, helps to identify segmental boundaries as they may correspond to fluctuations in the airflow and pressure signals.

Using acoustic landmarks, measurements were also obtained for VOT to distinguish between implosives and voiced plosives and to establish the boundaries of aspiration in the voiceless prenasalized stops. Additionally, the length of voicing of the nasal portions of $\mathbf{N}+$ stop sequences was measured to determine the extent of devoicing in such sequences. As mentioned previously, data for this preliminary study were collected from only one speaker.

\subsubsection{RESULTS}

\subsubsection{Voiced plosive/implosive contrast}

Other preliminary descriptions of Somali Chizigula contend that implosives occur only in prenasalized contexts (Odden et al. 2011). However, as illustrated in (2) above, implosives are present in all places of articulation and in both wordinitial and word-medial positions. Aerodynamically, the distinction between plosive and implosive is evidenced by a buildup of oral pressure prior to the plosive's release, and a lack of such buildup in the implosive segments.

Here we see a buildup in oral pressure prior to the release of the plosive as in (8a), leading to the release burst seen in the acoustic signal in (3). 
During the closure for the implosive, oral pressure is fairly stable due to the lowering of the larynx, as shown in (8b). In these examples, the shading highlights the oral stop closure.

(8) Aerodynamic data for voiced plosive and implosive contrast.

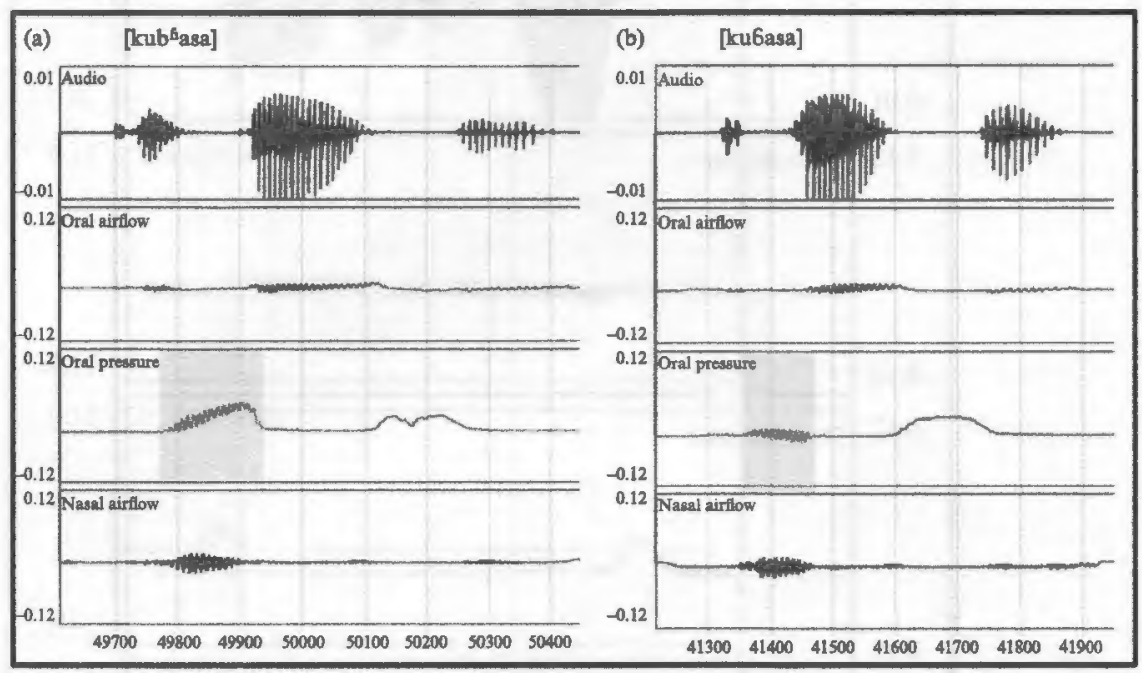

In addition to examining the buildup in oral pressure, we measured VOT for all tokens. Measurements ranged from $-98 \mathrm{~ms}$ to $-45 \mathrm{~ms}$ (average $-69 \mathrm{~ms}$ ) for the voiced plosives to $-103 \mathrm{~ms}$ to $-79 \mathrm{~ms}$ (average $-103 \mathrm{~ms}$ ) for the implosives. Owing to articulatory restrictions related to the tubing that relays oral pressure from the mask, we were unable to collect oral pressure data for the coronal and dorsal implosives. Aerodynamic data for prenasalized implosives is presented in the following section.

\subsubsection{2. $\mathrm{N}+$ stop sequences}

Examining the $\mathrm{N}+$ stop sequences, recall from (5) that there are both syllabic nasals followed by oral stops and prenasalized stops in the language. Aerodynamic data for the syllabic nasal in (9) illustrates robust nasal airflow during the nasal portion (shaded) followed by a sustained peak in oral pressure signifying an oral stop, with no burst release. 
(9) Aerodynamic data for [mpaka].

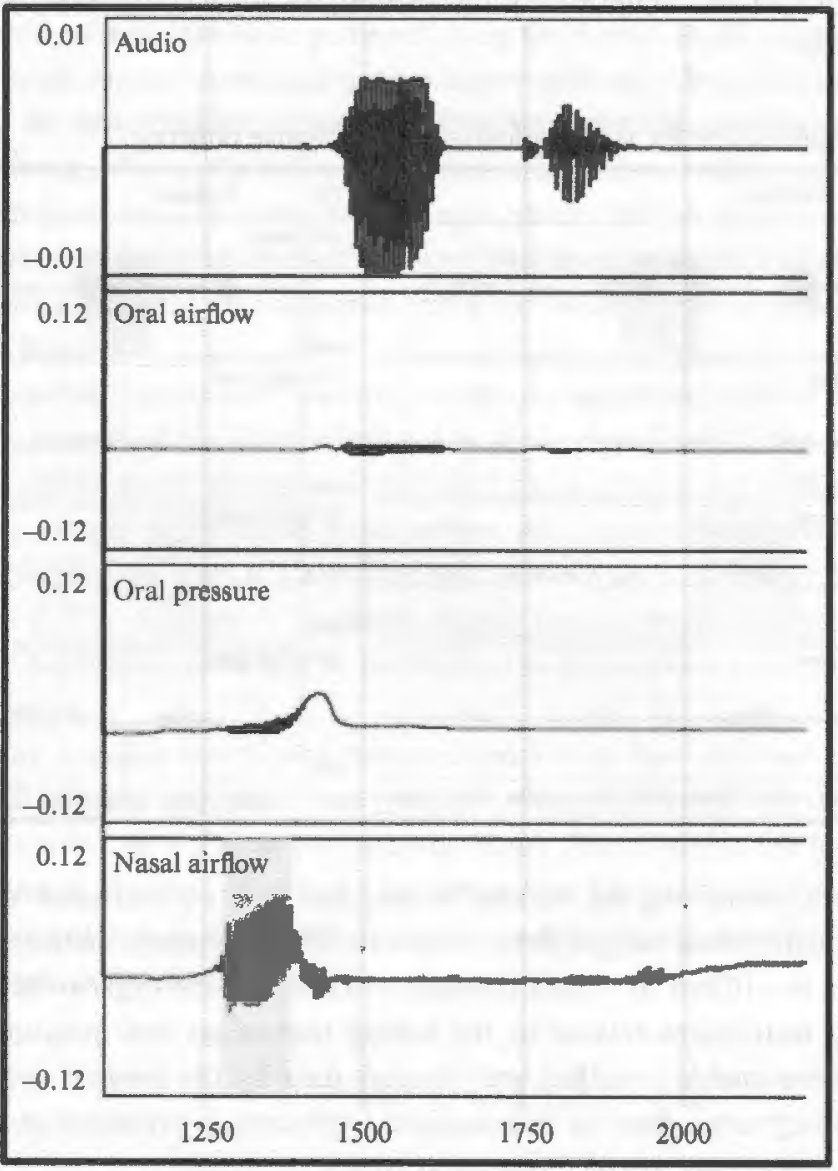

Likewise, in the prenasalized voiced stop in (10), nasal airflow is robust in the shaded nasal portion. However, the amplitude in the nasal tapers, and the oral stop is much shorter than the oral stop in (9)-the N+stop sequence containing the syllabic nasal is approximately twice as long as the prenasalized voiced stop (183ms and $91 \mathrm{~ms}$, respectively). Moreover, the oral pressure builds up as the nasal airflow declines before the release of the stop. 
(10) Aerodynamic data for [m6eho].

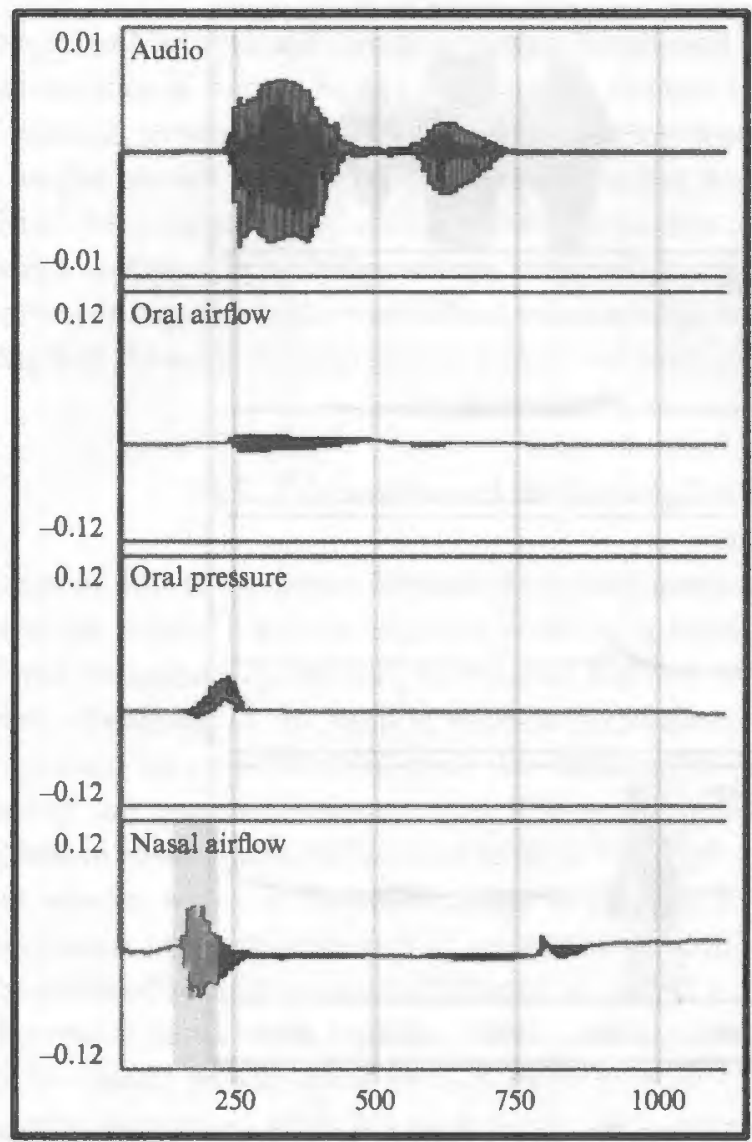

In (11), the inaudible nonsyllabic nasal in the voiceless $N+$ stop sequences is clearly visible in the form of nasal airflow (shaded) during the nasal portion of the sequence. Also visible is the buildup of oral pressure during the nasal portion, which results in aspiration following the release of the oral stop. 
(11) Aerodynamic data for [mphalala].

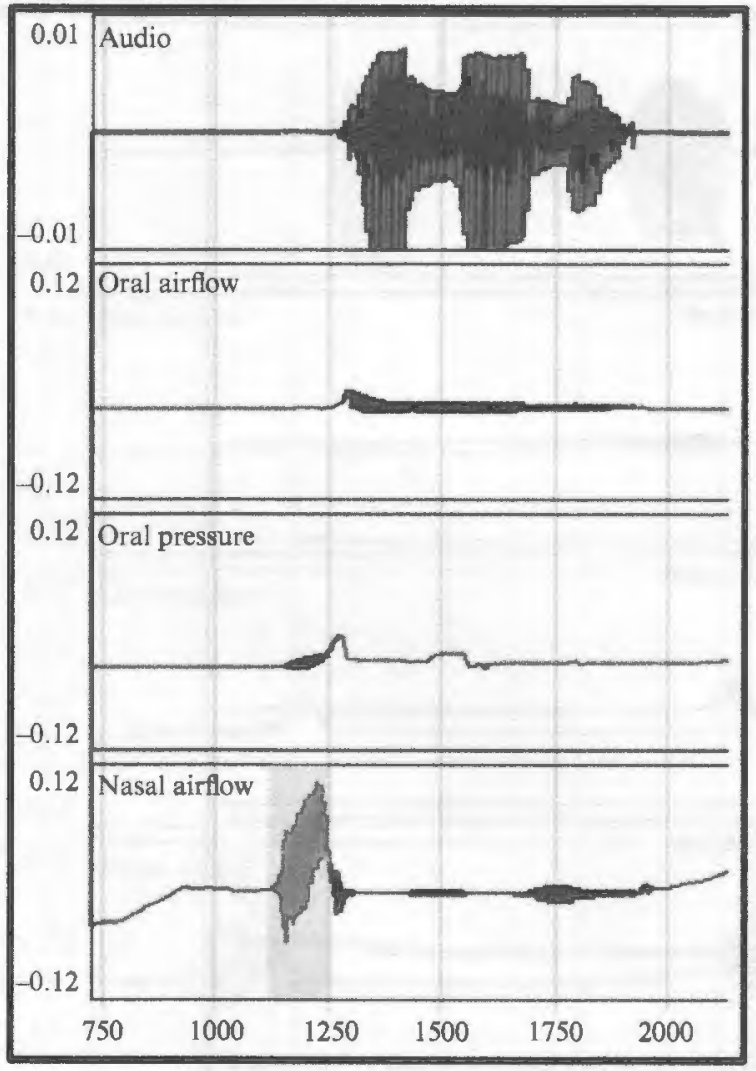

Measuring the length of the $\mathrm{N}+$ stop sequence here (which could not be done by looking solely at the acoustic signal), notice that the prenasalized voiceless stop is almost as long as the syllabic nasal followed by the voiceless plosive (at $156 \mathrm{~ms})$. Interestingly, recall that the VOT for these segments ranges from $59 \mathrm{~ms}$ to $109 \mathrm{~ms}$ - closer to the measurement for the entire $\mathrm{N}+$ stop sequence in the voiced prenasalized stops.

Overall, looking at the aerodynamic data has allowed us to confirm contrast between plosives and implosives, as well as to confirm the presence of nasal airflow in the voiceless prenasalized plosive. 


\subsection{Analysis and interpretation}

The use of both acoustic and aerodynamic data has allowed us to accurately describe the current state of stops in Somali Chizigula. In addition to acoustic details of the VOT contrast, showing that voiced plosives are aspirated and contrast with implosives, we also provide aerodynamic data to illustrate that there is robust nasal airflow in spite of the complete lack of voicing in the nasal portion of the voiceless prenasalized stops. Additionally, with the assistance of aerodynamic data, the length of the entire $\mathrm{N}+$ stop sequence in the prenasalized voiceless stops was found to be similar to the length of the entire $\mathrm{N}+$ stop sequence where the nasal was syllabic.

\subsection{Discussion and further implications}

Centuries of little to no contact between the Somali-Bantu and Tanzanian Kizigua speakers has created a unique linguistic situation in which the two varieties have developed independently. Initially, we believed that one resulting process was the complete effacement of the nasal in voiceless prenasalized segments. Using aerodynamic data, we are now able to prove that nasal airflow is present in spite of the absence of any perceptual acoustic cues. The current state of the devoiced nasal could lead to a reanalysis of effacement as ( $n t \rightarrow n t^{h} \rightarrow n t^{h} \rightarrow t^{h}$ ), and begs the question of whether we are witnessing a change in progress, or whether the nasal will remain devoiced in spite of the lack of perceptible acoustic cues.

The status of $\mathrm{N}+$ stop sequences in Bantu has played a role in conversations on the theoretical status of the segment. While some argue that nonsyllabic $\mathrm{N}+$ stop sequences should be accounted for as a single segment (Cohn 1990; Dart 1987; Durvasula 2009; Sagey 1986; Shadle \& Scully 1995), others argue for their treatment as a consonant cluster (Downing 2005). Acoustic measurements from our study illustrate that the VOT of prenasalized voiceless stops was similar in length to the length of the entire $\mathrm{N}+$ stop sequence in the prenasalized voiced stop. This finding is in agreement with the inverse relationship, seen in data on voiceless prenasalized consonants in Pokomo, between the duration of VOT and the length of the noisy portion of the nasal (Huffman \& Hinnebusch 1998).

Finally, these acoustic and aerodynamic data have helped us provide a more accurate description of Somali Chizigula, an endangered language, and they illustrate how the application of phonetic experimental methods can contribute to theoretical discussion and important documentation and revitalization efforts. 


\section{APPENDIX A: Wordlist}

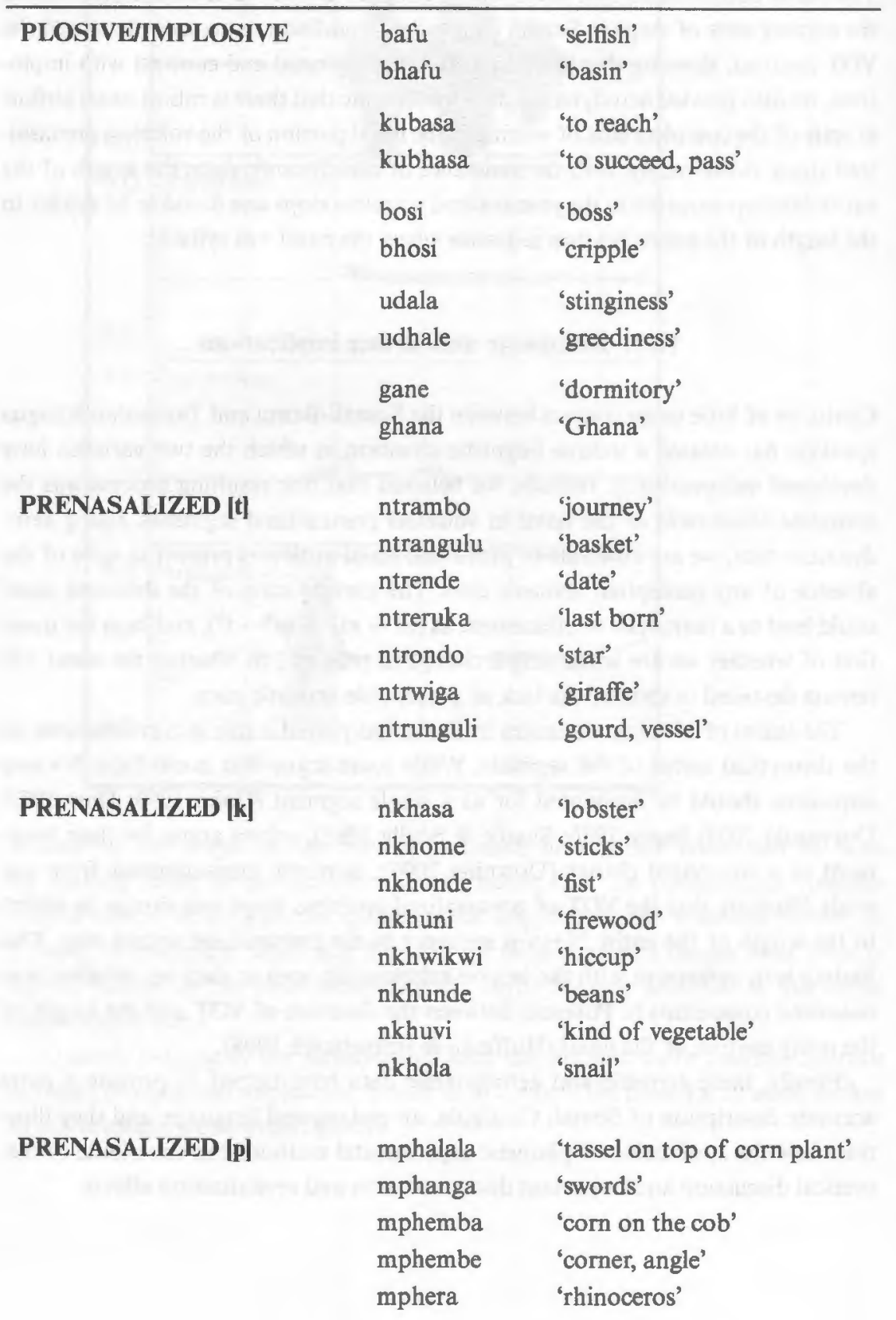




\begin{tabular}{|c|c|c|}
\hline PRENASALIZED [d] & ndimu & 'lemon' \\
\hline & nderi & 'rainy season' \\
\hline & ndima & 'work' \\
\hline & ndoni & 'boat' \\
\hline & ndevu & 'beard' \\
\hline & ndege & 'airplane' \\
\hline PRENASALIZED |g] & ngaga & 'hoof' \\
\hline & ngano & 'folk tale' \\
\hline & ngohe & 'eyelash' \\
\hline & ngola & 'knife' \\
\hline & ngamira & 'camel' \\
\hline & ngalawa & 'ship' \\
\hline & nguvu & 'strength' \\
\hline & ngwazo & 'hook' \\
\hline PRENASALIZED |b| & mbe & 'very' \\
\hline & mbeho & 'cold wind' \\
\hline & mboga & 'vegetable(s)' \\
\hline & mboko & 'banana tree' \\
\hline & mbuni & 'coffee plant' \\
\hline & mbisi & 'raw' \\
\hline PRENASALIZED [d] & ndodo & 'not enough' \\
\hline SYLLABIC NASAL & mtama & 'corn' \\
\hline & $\mathrm{mti}$ & 'tree' \\
\hline & mkoko & 'squash plant' \\
\hline & mkinyozi & 'barber' \\
\hline & mpaka & 'until' \\
\hline & mpenda & 'lover' \\
\hline & mdala & 'cheap person' \\
\hline & mdantro & 'liar, cheater' \\
\hline & mdyeni & 'visitor, stranger' \\
\hline & mdyima & 'old' \\
\hline & mganga & 'doctor' \\
\hline & mngereza & 'English speaker' \\
\hline & mbantu & 'person' \\
\hline & mbavi & 'thief' \\
\hline
\end{tabular}



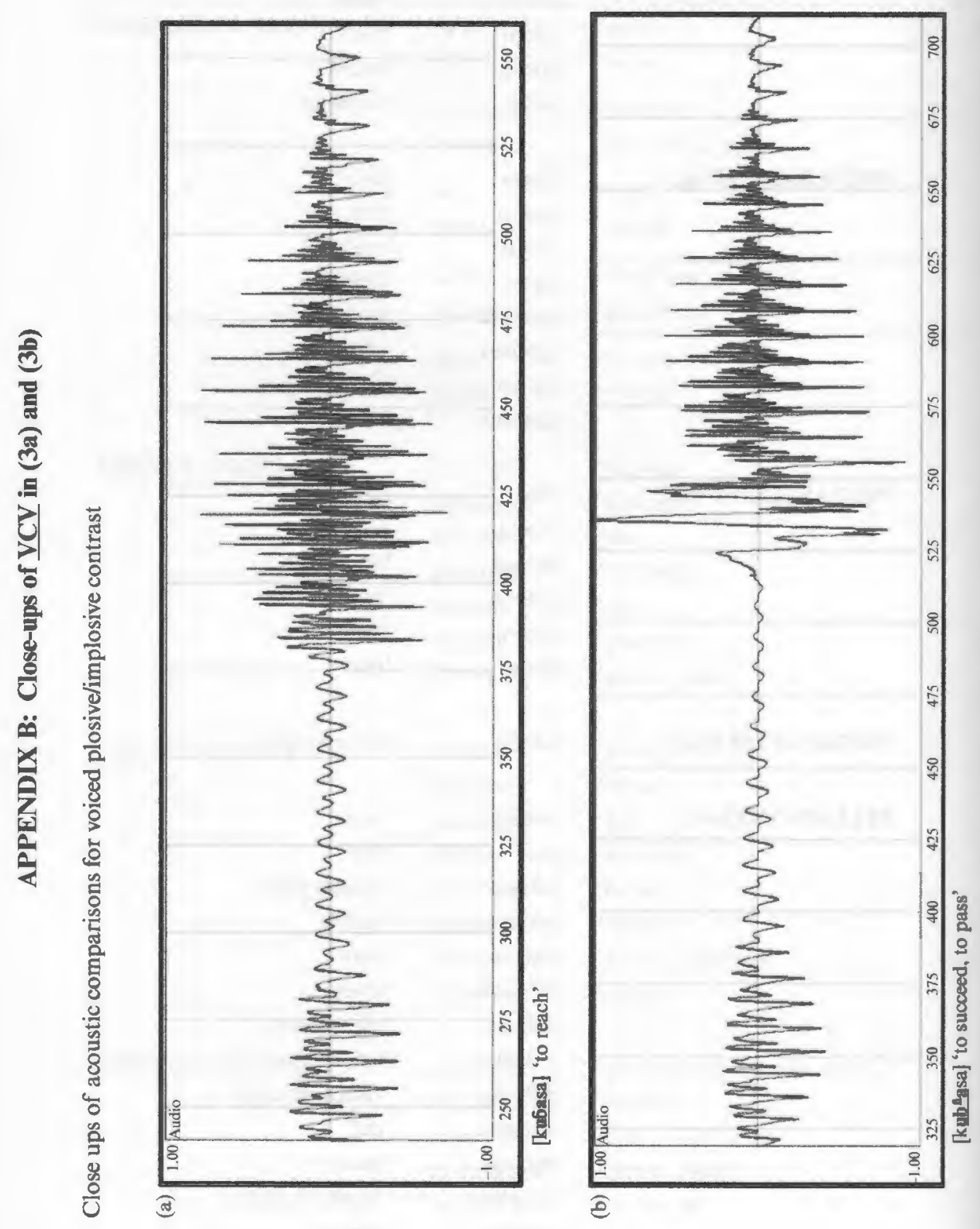


\section{Notes}

* The authors wish to thank Mr. Mwaliko Mberwa and the Somali Bantu Zigua Community in Boise for their tremendous support throughout this project, as well as Haley Boone for help with inter-rater reliability for acoustic measurements. We are also indebted to the editors of this volume, as well as to our anonymous reviewers for suggestions and critique that helped us greatly improve this manuscript. This research was funded through a Boise State University Arts and Humanities Institute Fellowship. Work on the larger Chizigula documentation project is also supported by the Idaho Humanities Council.

1. Land that now makes up southern, central, and northeastern Somalia was colonized as Italian Somaliland from 1889 until 1936. During this time, Italian was the official language of the colony.

2. Although tone has been reported in Tanzania Kizigua, and a preliminary analysis on Somali Chizigula verbal tone is presented in Pillion (2013), we have not included tone in this chapter as our analysis of it is still in development.

3. In the acoustic illustrations, the gray vertical lines demark $50 \mathrm{~ms}$ intervals unless otherwise noted.

4. The presence of the nasal is only audible with the addition of a CV prefix.

5. Gray vertical lines demark $25 \mathrm{~ms}$ intervals in the examples in (6).

6. The masks and transducers used for this investigation are the 2013 model of the Scicon R\&D system described in chapter 3 of Ladefoged (2003).

\section{References}

Cohn, ABigall C. 1990. Phonetic and phonological rules of nasalization. Working Papers in Phonetics 76.1-223.

DaRT, SARAH N. 1987. An aerodynamic study of Korean stop consonants: Measurements and modeling. Journal of the Acoustical Society of America 81.138-147.

Dayley, Jon P., Mwaliko Mrerwa, \& Michal Temkin Martinez, eds. 2017. ChizigulaEnglish/English-Chizigula Dictionary. Ms., Boise State University. Online: http://somalichizigula.webonary.org/.

DiCanio, Christian T. 2012. Cross-linguistic perception of Itunyoso Trique tone. Journal of Phonetics 40.672-688.

DOWNING, LAURA J. 2005. On the ambiguous segmental status of nasals in homorganic NC sequences. The internal organization of phonological segments, ed. by Marc van Oostendorn \& Jeroen M. van de Weijer, 183-216. Berlin: Mouton de Gruyter.

DuRvasurA, Karthik. 2009. Understanding nasality. Ph.D. dissertation, University of Delaware.

Hout, Katherine. 2012. The vocalic phonology of Mushunguli. B.A. thesis, Ohio State University. Online: http://kb.osu.edu/dspace/handle/1811/53373.

Hudu, Fusheini Angulu, Amanda Miller, \& Douglas Pulleyblank. 2009. Ultrasound imaging and theories of tongue root phenomena in African languages. Paper presented at Language Documentation \& Linguistic Theory 2, School of Oriental and African Studies, London. Online: https://www.researchgate.net/publication/239853987_Ultrasound imaging_and_theories_of_tongue_root_phenomena_in_African_languages. 
Huffman, Marie K., \& Thomas J. Hinnebusch. 1998. The phonetic nature of 'voiceless' nasals in Pokomo: Implications for sound change. Journal of African Languages and Linguistics 19.1-19.

Hyman, LARRY M. 2003. Segmental phonology. The Bantu languages, ed. by Derek Nurse \& Gerard Philippson, 42-58. London \& New York: Routledge.

Kenstowicz, Michael. 1989. Tone and accent in Kizigua-a Bantu language. Certamen phonologicum I: Papers from the 1987 Cortona Phonology Meeting, ed. by P. M. Bertinetto \& M. Loporcaro, 177-188. Turin: Rosenberg \& Sellier.

Kenstowicz, Michael, \& Charles W. Kisseberth. 1990. Chizigula tonology: The word and beyond. The phonology-syntax connection, ed. by Sharon Inkelas et al., 163-194. Chicago: University of Chicago Press.

Kisbey, Walter H. 1906. Zigula-English dictionary. London: Society for Promoting Christian Knowledge.

Kisseberth, Charles W. 1992. Metrical structure in Zigula tonology. African linguistic contributions presented in honor of Ernst Westphal, ed. by D. F. Gowlett, 227-259. Pretoria: Via Afrika.

Ladefoged, Peter. 2003. Phonetic data analysis: An introduction to fieldwork and instrumental techniques. Malden, MA: Blackwell.

Lee-Kim, Sang-Im, Shigeto Kawahara, \& Seunghun J. Lee. 2014. The 'whistled' fricative in Xitsonga: Its articulation and acoustics. Phonetica 71.50-81.

Lewis, M. Paul, Gary F. Simons, \& Charles D. Fennig, eds. 2015. Ethnologue: Languages of the World 17th ed. Dallas, TX: SIL International. Online: http://www.ethnologue. com.

Lisker, Leigh, \& ARThur Abramson. 1964. A cross-language study of voicing in initial stops: Acoustical measurements. Word 20(3).384-422.

Maddieson, IAN. 1993. Investigating Ewe articulations with electromagnetic articulography. Forschungsberichte des Instituts fur Phonetik und Sprachliche Kommunikation der Universitate Munchen 31.181-214.

Maddieson, IAN. 2003. The sounds of the Bantu languages. The Bantu languages, ed. by Derek Nurse \& Gerard Philippson, 15-41. London \& New York: Routledge.

Maddieson, Ian, \& Peter Ladefoged. 1993. Phonetics of partially nasal consonants. Phonetics and Phonology 5.251-301.

Miller, Amanda L. 2008. Click cavity formation and dissolution in IsiXhosa: Viewing clicks with high-speed ultrasound. Paper presented at the 8th International Seminar on Speech Production. Online: http://issp2008.loria.fr/Proceedings/PDF/issp2008-28.pdf.

Miller, AmANDa L. 2011. The representation of clicks. The Blackwell companion to phonology, vol. 2: Suprasegmental and prosodic phonology, ed. by Marc van Oostendorp et al., 416-439. Malden, MA: Blackwell.

Miller, Amanda L., Johanna Brugman, Bonny Sands, Levi Namaseb, m. Exter, \& c. Collins. (2009). Differences in airstream and posterior place of articulation among N|uu lingual stops. Journal of the International Phonetic Association 39.129-161.

Miller, Amanda L., \& Kenneth B. Finch. 2011. Corrected high frame rate anchored ultrasound with software alignment. Journal of Speech, Language and Hearing Research 54.471-486.

Mochiwa, Zakaria S. M. 2008. Kizigula lexicon. Dar es Salaam: Languages of Tanzania Project. 
ODden, David, et al. 2011. The Mushunguli-Chizigula language of Somalia. Online: http:// www.ling.ohio-state.edu/ odden/mushunguli/.

O'Grady, William, Amy J. Schafer, Jawee Perla, On-Soon Lee, \& Julia Wieting. 2009. A psycholinguistic tool for the assessment of language loss. Language Conservation and Documentation 3.100-112.

Peterson, Gordon E., \& Ilse Lehiste. 1960. Duration of syllable nuclei in English. Journal of the Acoustical Society of America 32.693-703.

Pillion, Elizabeth. 2013. An autosegmental analysis of verbal tone in Mushunguli. B.A. thesis, Ohio State University. Online: http://kb.osu.edu/dspace/handle/1811/54798.

SAGEY, ElizABETH. 1986. The representation of features and relations in non-linear phonology. Cambridge, MA: MIT dissertation.

Shadle, Christine H., \& C. Scully. 1995. An articulatory-acoustic-aerodynamic analysis of [s] in CVC sequences. Journal of Phonetics 23.53-66.

Thieberger, Nicholas. 2009. Steps toward a grammar embedded in data. New challenges in typology: Transcending the borders and refining the distinctions, ed. by Patience Epps \& Alexandre Arkhipov, 389-408. New York: Mouton de Gruyter.

Traill, Anthonx. 1985. Phonetic and phonological studies of IX6ठ Bushman Hamburg: Helmet Buske.

Tse, Holman. 2013. The diachronic emergence of retroflexion in Somali Bantu Kizigua: Internal motivation or contact-induced change? Paper presented at the 44th Annual Conference on African Linguistics, Georgetown University, Washington, DC. Online: http://www.lingref.com/cpp/acal/44/paper3145.pdf.

Woodeury, Anthony C. 2011. Language documentation. The Cambridge Handbook of Endangered Languages, ed. by Peter K. Austin \& Julia Sallabank, 159-186. Cambridge, U.K.: Cambridge University Press. 